\title{
nature
}

\section{Private vs public genomics?}

Commercial sequencing of genomes has stimulated scientific progress. But the increasing value of such companies risks exacerbating the conflict between the interests of investors and of the public. Both need to worry.

W hat was the purpose of the announcement by Celera Genomics on Monday that it now has DNA sequences totalling more than 90 per cent of the genome in its database? If the company's goal was to raise the value of its shares, it certainly succeeded. On the day of the announcement, the shares, which had ended the previous day of trading at US $\$ 187$, leapt at one stage by more than $\$ 70$, and ended the day at $\$ 242$ - giving the company, at least on paper, a market value of $\$ 6.3$ billion.

But that explanation is not totally persuasive. Celera's shares, like those of a raft of other genomics-based companies, have been rising steadily for several weeks, partly because of various scientific announcements, such as the successful sequencing of human chromosome 22, and also because some investors are turning to biotechnology following a spree with Internet stocks.

Yet neither is a purely scientific explanation convincing. The 90 per cent 'milestone' announced with pride by Celera's president (and prime mover) Craig Venter, and the fact that "greater than 97 per cent of all human genes" are now present in its database, are somewhat arbitrary benchmarks. Both are considerable achievements, and some of these data are no doubt already proving of significant value to the private subscribers to the database. But, as Venter himself admits, much remains to be done before anyone understands what the newly discovered genes represent and before the data can be assembled into anything resembling a complete genome sequence.

Whatever the motivation for the announcement, one of its most significant aspects was that it underlined the basic complementarity between the private and public sequencing efforts. Celera officials openly admit that the company has only been able to achieve the 90 per cent figure by drawing extensively on sequence data already made openly and immediately available through the Human Genome
Project (see page 119). As their statement puts it, "the combination of these two complementary genome sequencing and assembly approaches greatly reduces the time for Celera to finish the sequence of the human genome".

All the more disturbing, therefore, that Celera clings to the right to control the use of its own data, while freely using that obtained from publicly financed sources. Venter's comments that the full consensus sequence data, once published in a scientific journal, will be made "freely available" to researchers around the world, are welcome. But the company's caveat that this will only be done "under a nonredistribution agreement" raises the spectre that scientists seeking to use these data in, for example, the development of potential commercial products will find themselves constrained by strict conditions.

Celera has a right to benefit directly from its own heavy investment in sequencing, and such sequencing efforts could be as valuable to public sequencing initiatives as the latter have already been to Celera's. But Celera should take note of the proposed National Institutes of Health guidelines on the use of research materials (http://www. nih.gov/od/ott/RTguide_final.htm). Although not bound by the guidelines, Celera and other companies should heed the warning they give against excessive burdens of chains of licensing requirements.

Are the interests of investors and the public at odds? Celera's playing of the market increasingly threatens such a conflict: the financial expectations now being placed upon the genomics industry will necessitate secrecy and potentially burdensome licensing, whereas public funding bodies rightly seek the greatest possible access to, and freedom to build on, raw sequence data. Given the benefits of rapid development of treatments of disease, investors could find their interests set not only against those of academics and science funding agencies but also the public at large. Remember Monsanto?

\section{Millennium bugs}

\section{AIDS in Africa threatens the United States. It should act accordingly.}

T he United Nations (UN) security council this week had, for the first time in its history, a health issue on its agenda: AIDS in Africa. Al Gore, who chaired the meeting, announced that the US administration had asked Congress for $\$ 150$ million for vaccine research and prevention programmes in Africa. Will the money ever materialize? Will it be new money? The dismal history of such pledges gives grounds for scepticism.

Nevertheless, and despite the horrific scale of the problems in Africa, there is room for hope. Three years ago, malaria was an invisible disease. Since then research organizations, donor agencies and drug companies have created a consortium to stimulate research and strategies to combat the disease, while companies have teamed up to relaunch drug discovery. These new structures and their plans have their flaws (see Nature Medicine 5,1334; 1999), but they testify to movement and commitment where before there was only stagnation. Similar groups of people will meet in Cape Town next month for a major meeting whose goal is to do the same for tuberculosis.
Media attention and political commitment are essential to provide the climate for such initiatives to flourish. Rightly, Al Gore has pointed to the absolute necessity of investment in basic health infrastructure and domestic competence, and to the need for African governments themselves to lift health from the bottom of their spending priorities. Wisely, he has characterized AIDS in Africa as a security threat to the United States' own interests, through its destabilizing of the structure of whole societies and economies.

This welcome recognition of the socio-economic impact of disease may help nudge the United States to take greater leadership and participation in global health issues. Multilateral initiatives are the way forward, but the experience with malaria has shown that the United States is reluctant to participate in ventures other than on its own terms. If Gore is serious, a first step would be for the United States to repay its debts to the UN technical agencies that are often in the front line of the war against disease in Africa and begin to play an active role in modernizing them and their programmes. 